\title{
Characteristics of brown carbon in the urban Po Valley atmosphere
}

\author{
Francesca Costabile ${ }^{1}$, Stefania Gilardoni ${ }^{2}$, Francesca Barnaba ${ }^{1}$, Antonio Di Ianni ${ }^{1}$, Luca Di Liberto ${ }^{1}$, \\ Davide Dionisi $^{1}$, Maurizio Manigrasso ${ }^{3}$, Marco Paglione ${ }^{2}$, Vanes Poluzzi ${ }^{4}$, Matteo Rinaldi ${ }^{2}$, Maria Cristina Facchini ${ }^{2}$, \\ and Gian Paolo Gobbi ${ }^{1}$ \\ ${ }^{1}$ Institute for Atmospheric Sciences and Climate (ISAC), National Research Council (CNR), Rome, Italy \\ ${ }^{2}$ Institute for Atmospheric Sciences and Climate (ISAC), National Research Council (CNR), Bologna, Italy \\ ${ }^{3}$ INAIL, Rome, Italy \\ ${ }^{4}$ ARPA ER, Bologna, Italy \\ Correspondence to: Francesca Costabile (f.costabile@isac.cnr.it)
}

Received: 30 December 2015 - Published in Atmos. Chem. Phys. Discuss.: 1 February 2016

Revised: 13 December 2016 - Accepted: 17 December 2016 - Published: 5 January 2017

\begin{abstract}
We investigate optical-microphysical-chemical properties of brown carbon $(\mathrm{BrC})$ in the urban ambient atmosphere of the Po Valley. In situ ground measurements of aerosol spectral optical properties, $\mathrm{PM}_{1}$ chemical composition (HR-ToF-AMS), and particle size distributions were carried out in Bologna. $\mathrm{BrC}$ was identified through its wavelength dependence of light absorption at visible wavelengths, as indicated by the absorption Ångström exponent (AAE). We found that $\mathrm{BrC}$ occurs in particles with a narrow monomodal size distribution peaking in the droplet mode, enriched in ammonium nitrate and poor in black carbon (BC), with a strong dependance on OA-to-BC ratios, and $\mathrm{SSA}_{530}$ of $0.98 \pm 0.01$. We demonstrate that specific complex refractive index values $\left(k_{530}=0.017 \pm 0.001\right)$ are necessary in addition to a proper particle size range to match the large AAEs measured for this $\mathrm{BrC}\left(\mathrm{AAE}_{467-660}=3.2 \pm 0.9\right.$ with values up to 5.3). In terms of consistency of these findings with literature, this study
\end{abstract}

i. provides experimental evidence of the size distribution of $\mathrm{BrC}$ associated with the formation of secondary aerosol;

ii. shows that in the lower troposphere AAE increases with increasing $\mathrm{OA}-$ to- $\mathrm{BC}$ ratios rather than with increasing $\mathrm{OA}$ - contributing to sky radiometer retrieval techniques (e.g., AERONET);

iii. extends the dependence of $\mathrm{AAE}$ on BC-to-OA ratios previously observed in chamber experiments to ambient aerosol dominated by wood-burning emissions.
These findings are expected to bear important implications for atmospheric modeling studies and remote sensing observations as regards the parametrization and identification of $\mathrm{BrC}$ in the atmosphere.

\section{Introduction}

Aerosol has an important role in the Earth's climate with both direct and indirect effects; in addition, it affects air quality and atmospheric chemistry. At present, our understanding of the light-absorbing aerosol types is incomplete (see reviews by Laskin et al., 2015; Moise et al., 2015). An important absorber of solar radiation in the UV-vis region is atmospheric carbonaceous aerosol (IPCC, 2013). In the classification of its components proposed by Pöschl (2003), visiblelight-absorbing properties ranged between two extremes. On one side, there is black carbon (BC), refractory material that strongly absorbs light over a broad spectral range. On the other side, there is colorless organic carbon (OC), nonrefractory material, with no absorption or little absorption in the UV-vis spectral range. There is a gradual decrease of thermochemical refractiveness and specific optical absorption going from $\mathrm{BC}$ graphite-like structures to non-refractive and colorless OC (Laskin et al., 2015). A broad range of colored organic compounds has recently emerged in the scientific literature for their possible role in the Earth's radiative transfer and therefore its climate (Laskin et al., 2015; Moise et al., 2015). 
The term brown carbon $(\mathrm{BrC})$ has emerged to describe this aerosol with an absorption spectrum smoothly increasing from the visible (vis) to the near-UV wavelengths, with a strong wavelength dependance of the light absorption coefficient $\left(\lambda^{-2}-\lambda^{-6}\right)$ (Andreae and Gelencsér, 2006; Moosmüller et al., 2011; Bond et al., 2013; Laskin et al., 2015; Moise et al., 2015). BrC lacks a formal analytical definition (Bond et al., 2013). In this study, we will identify BrC through its high values (2-6) of the absorption Ångström exponent (AAE), a parameter describing the wavelength $(\lambda)$ dependent absorption coefficient $\left(\sigma_{\mathrm{a}}\right)$ of light by aerosol, written as

$\operatorname{AAE}(\lambda)=-\frac{\mathrm{d} \ln \left(\sigma_{\mathrm{a}}\right)}{\operatorname{dln}(\lambda)}$.

What is known about $\mathrm{BrC}$ aerosol is that it is organic matter with both primary and secondary sources (Laskin et al., 2015). Primary BrC can be emitted together with BC from low-temperature combustion processes, like wood combustion (Andreae and Gelencsér, 2006). Secondary organic aerosol (SOA) formed in the atmosphere also contributes to light-absorbing-carbon (Moise et al., 2015, and references therein), but only a few field measurement studies have analyzed the BrC associated with SOA (Zhang et al., 2011; Saleh et al., 2013; Zhang et al., 2013; Gilardoni et al., 2016).

Numerous evidences indicate increased absorption towards UV for aerosol particles high in nitrate (e.g., Jacobson, 1999; Zhang et al., 2013), sulfate (Lee et al., 2013; Song et al., 2013; Powelson et al., 2014; Lin et al., 2014), and ammonium (Shapiro et al., 2009; Noziere et al., 2009; Bones et al., 2010; Noziere et al., 2010; Sareen et al., 2010; Updyke et al., 2012; Flores et al., 2014; Lin et al., 2015). Lin et al. (2014) reported the formation of light-absorbing SOA constituents from reactive uptake of isoprene epoxydiols onto preexisting acidified sulfate seed aerosol as a potential source of secondary $\mathrm{BrC}$ under tropospheric conditions. Powelson et al. (2014) discussed $\mathrm{BrC}$ formation by aqueous-phase carbonyl compound reactions with amines and ammonium sulfate. Lee et al. (2013) studied the likely but uncertain effect of sulfate on the formation of light-absorbing materials and organonitrogen via aqueous glyoxal chemistry in aerosol particles. Song et al. (2013) observed significant light absorption at 355 and $405 \mathrm{~nm}$ for SOA formed from an $\alpha$-pinene $+\mathrm{O}_{3}$ $+\mathrm{NO}_{3}$ system only in the presence of highly acidic sulfate seed aerosols under dry conditions. Several studies demonstrated the importance of ammonium, both as a catalyst and as a reactant, in the formation of light-absorbing products (Powelson et al., 2014; Laskin et al., 2015). SOA formation can occur in both the gas and condensed phases. Recently, efficient SOA production has been recognized in cloud and fog drops and water-containing aerosol: water-soluble products of gas-phase photochemical reactions may dissolve into an aerosol aqueous phase and form SOA through further oxidation, this SOA being referred to as "aqSOA" (Ervens et al., 2011; Laskin et al., 2015). AqSOA formation impacts total
SOA mass and aerosol size distributions by adding mass to the so-called "droplet mode" (Ervens et al., 2011). Meng and Seinfield (1994) showed that the aerosol "droplet mode" in urban areas is the result of activation of smaller particles to form fog, followed by aqueous-phase chemistry and fog evaporation. It was demonstrated that aqSOA formation can affect aerosol optical properties by adding light-absorbing organic material at UV wavelengths (Shapiro et al., 2009; Ervens et al., 2011; Gilardoni et al., 2016). Gilardoni et al. (2016) demonstrated that in the ambient atmosphere the aqSOA from biomass burning contributes to the $\mathrm{BrC}$ budget and exhibits light absorption wavelength dependence close to the upper bound of the values observed in laboratory experiments for fresh and processed biomass-burning emissions.

Despite the efforts made, relations between optical properties and chemical composition of organic compounds with spectrally variable light absorption (high AAE) are poorly understood (Laskin et al., 2015). A number of previous works (Shinozuka et al., 2009; Russell et al., 2010; Arola et al., 2011) studied how the organic aerosol (OA) mass fraction $\left(f_{\mathrm{OA}}\right)$ relates to $\mathrm{AAE}$ and to single scattering albedo (SSA), the ratio of scattering to extinction, a key parameter in understanding aerosol warming or cooling effect. Results from in situ measurements on the C-130 aircraft (Central Mexico) during MILAGRO (Russell et al., 2010) showed that both organics and dust increase AAE values. Russell et al. (2010) showed a direct correlation between AAE and $f_{\mathrm{OA}}$. On the basis of the same data, Shinozuka et al. (2009) showed that AAE generally increases as $f_{\mathrm{OA}}$ or SSA increases. Saleh et al. (2014) burnt a selection of biomasses in a combustion chamber, varying the combustion parameters to obtain a range of $\mathrm{BC}$-to-OA ratios. This ratio, the relative proportions of $\mathrm{BC}$ and $\mathrm{OA}$ mass, depends on fire characteristics and plume age, and it determines aerosol color from black to brown to white as the ratio decreases. Saleh et al. (2014) findings link the extent of absorbance to the BC-to$\mathrm{OA}$ ratio for aged and fresh biomass-burning aerosols. If confirmed, this link has the potential to be a strong predictive tool for light-absorbing properties of biomass-burning aerosols (Bellouin, 2014; Moise et al., 2015). Following the approach of Saleh et al. (2014), Lu et al. (2015) reviewed available emission measurements of biomass-burning and biofuel combustion and found similar results indicating that AAE of the bulk OA decreases with the increasing BC-to$\mathrm{OA}$ ratio. They conclude that the absorptive properties of OA from biomass/biofuel burning depend strongly on burning conditions and weakly on fuel types and atmospheric processing.

In this study, we investigate optical-microphysicalchemical properties of $\mathrm{BrC}$ in the ambient urban atmosphere. In situ ground ambient data of chemical (high-resolution time-of-flight aerosol mass spectrometer, HR-ToF-AMS), optical ( $3 \lambda$ nephelometer and $3 \lambda$ particle soot absorption photometer, PSAP), and microphysical (SMPS and APS) aerosol properties were taken during two field measurements 
in Bologna, Po Valley. BrC is identified through the AAE of the non-dust bulk aerosol. First (Sect. 4.1), we investigate $\mathrm{BrC}$ properties by relating the AAE to the aerosol size, and in particular to the aerosol types with known size distribution e.g., the droplet mode. We match AAE patterns measured for $\mathrm{BrC}$ to those theoretically expected for $\mathrm{BrC}$ in the ambient aerosol (based on the Mie theory). The AAE and aerosol size are then related to $\mathrm{PM}_{1}$ major chemical components (nitrate, $\mathrm{OA}, \mathrm{BC}$, sulfate, and ammonium) and to the $\mathrm{BC}$-to-OA ratio. Then, we show a case study to illustrate the major features of $\mathrm{BrC}$ (Sect. 4.3). Finally, findings are discussed in comparison with the literature to explore their general validity (Sect. 4.4).

\section{Experimental}

Optical, chemical, and microphysical aerosol properties were measured, in the framework of the Supersite project funded by the Emilia-Romagna region, at the urban background site of Bologna $\left(44^{\circ} 31^{\prime} 29^{\prime \prime}\right.$ lat, $11^{\circ} 20^{\prime} 27^{\prime \prime}$ long), in the Po Valley (Italy). Two measurement campaigns lasting 1 month were carried out: 22 October-13 November 2012 (fall campaign) and 1-27 February 2013 (winter campaign). Measurement setup is described below.

\subsection{Measurement cabins and sampling lines}

Equipment was set up in two different cabins, located side by side. Optical properties and coarse fraction size distributions were measured in the same cabin, all the instruments set up on the same inlet system equipped with a $\mathrm{PM}_{10}$ head. In the cabin, external air was pumped into a stainless steel tube (length of $4.0 \mathrm{~m}$ ) by an external pump ensuring a laminar flow (Reynolds number $<2000$ ). The cabin was kept at a temperature of $20-25^{\circ} \mathrm{C}$. The difference between air temperature and dew point was enough to dry the sampled air. Chemical properties and fine and ultrafine particle number size distribution (PNSD) were measured through a separate stainless steel inlet tube equipped with a $\mathrm{PM}_{1}$ head.

\subsection{Optical measurements}

Spectral optical properties in the visible range were measured online with 5 min time resolution. Dry aerosol absorption coefficients, $\sigma_{\mathrm{a}}(\lambda)$, at three wavelengths $(\lambda=467,530$, $660 \mathrm{~nm}$ ) were measured by a three-wavelength PSAP (Radiance Research), together with dry aerosol scattering coefficients $\left(\sigma_{\mathrm{s}}(\lambda)\right)$ at 450,525 , and $635 \mathrm{~nm}$, measured by an integrating nephelometer (Ecotech, mod. Aurora 3000). Like all filter-based methods, PSAP suffers from a number of measurement artifacts, including an overestimate of absorption due to light scattering effects, and a dependence of measurements on filter transmittance (Tr) (Lack et al., 2008; Virkkula, 2010; Bond et al., 2013; Backman et al., 2014). We corrected raw PSAP data after the iterative procedure described by Virkkula (2010), where only data with $\operatorname{Tr}>0.7$ were retained. The wavelength-resolved $\sigma_{\mathrm{S}}(\lambda)$ necessary to correct PSAP raw data were taken from nephelometer data corrected for truncation (Anderson and Ogren, 1998; Bond, 2001; Müller et al., 2011). The scattering error after the truncation error correction is $\frac{\delta\left(\sigma_{\mathrm{s}}\right)}{\sigma_{\mathrm{s}}}=0.02$ (Bond et al., 2013). The uncertainty of $\sigma_{\mathrm{a}}(\lambda)$ derived from PSAP data after these corrections has been estimated to be $\frac{\delta\left(\sigma_{\mathrm{a}}\right)}{\sigma_{\mathrm{a}}}=0.2$ (Virkkula, 2010; Lack et al., 2008; Bond et al., 1999; Virkkula, 2010; Cappa et al., 2008). The PSAP-derived $\sigma_{\mathrm{a}}(\lambda)$ can be considered an upper limit of the "true" value (Subramanian et al., 2007; Lack et al., 2008).

After all corrections, data were checked (by visual inspection) to find any outlier/low values that could significantly influence data statistics. These values could be due to variability in the measurements or to experimental errors. According to manufacturers, (i) PSAP sensitivity is $<1 \mathrm{Mm}^{-1}$ and measurement range is $0-50 \mathrm{Mm}^{-1}$, and (ii) the lower detectable limit of the nephelometer is $0.3 \mathrm{Mm}^{-1}$, with calibration tolerance of $\pm 4 \mathrm{Mm}^{-1}$ and measurement range 0 $2000 \mathrm{Mm}^{-1}$. A few data (124 records with $\sigma_{\mathrm{a}}<1 \mathrm{Mm}^{-1}$, less than 20 records with $\sigma_{\mathrm{s}}<10 \mathrm{Mm}^{-1}$, and some points with $\sigma_{\mathrm{s}}>700 \mathrm{Mm}^{-1}$ ) were discarded, as they were considered dubious values (comparing to data variability during the field campaigns, illustrated in Fig. S1 of the Supplement).

\subsection{Chemical measurements}

Chemical composition of atmospheric aerosol particles were characterized online with an HR-ToF-AMS (Aerodyne Research Inc., Billerica) (DeCarlo et al., 2006). The HR-ToFAMS measured the chemical composition of non-refractory $\mathrm{PM}_{1}$ (nr-PM $\mathrm{PM}_{1}$, i.e., sulfate, nitrate, ammonium, chloride, and organic aerosol. The instrument alternated acquisition in $\mathrm{V}$ mode (higher sensitivity and lower mass spectral resolution) and $\mathrm{W}$ mode (lower sensitivity and higher mass spectral resolution) every $2.5 \mathrm{~min}$. Quantitative information discussed here corresponds to the data collected in V mode. While operating in $\mathrm{V}$ mode, the instrument measures particle size distribution based on time of flight (Jimenez et al., 2003). HRToF-AMS data were analyzed using SQUIRRELL v1.51 and PIKA v1.10 software (D. Sueper, University of Colorado, Boulder, CO, USA) within Igor Pro 6.2.1 (WaveMetrics, Lake Oswego, OR). Collection efficiency was calculated according to Middlebrook et al. (2012) based on aerosol chemical composition and relative humidity. Data validation was performed by comparison with offline measurements of sulfate, ammonium, and nitrate concentrations in $\mathrm{PM}_{1}$ aerosol samples. The HR-ToF-AMS aerosol sample line was dried below $40 \%$ RH with a Nafion drier. The uncertainty of the AMS-derived OA was assumed to be $\frac{\delta(\mathrm{OA})}{\mathrm{OA}}=0.2$ according to Quinn (2008). 


\subsection{Particle number size distributions}

PNSDs were measured by combining a commercial scanning mobility particle sizer (SMPS, TSI model 3080, with long-DMA, TSI model 3081, equipped with a water-based condensation particle counter, CPC, TSI model 3787) and a commercial aerodynamic particle sizer (APS, TSI). Particles from 14 to $750 \mathrm{~nm}$ of mobility diameter were sized and counted by the SMPS; particles from 0.5 to $20 \mu \mathrm{m}$ of aerodynamic diameter were sized and counted by the APS (the procedure to fit the two PNSDs is described in Sect. 3.2). SMPS data were corrected for penetration errors through the sampling line, penetration efficiency due to diffusion losses (calculated according to Hinds, 1999) being higher than $98 \%$ for particles bigger than $14 \mathrm{~nm}$. An impactor $(50 \%$ cutoff diameter $=0.677 \mu \mathrm{m}$ ) was used to remove larger particles from the SMPS sampling line.

\section{Data analysis}

Data measured by all the instruments were merged in a single 5 min time resolution dataset. This dataset includes the time series of the following variables: $\sigma_{\mathrm{a}}(\lambda)$ and $\sigma_{\mathrm{s}}(\lambda), \mathrm{OA}, \mathrm{NO}_{3}^{-}$, $\mathrm{SO}_{4}^{2-}, \mathrm{NH}_{4}^{+}$, and PNSD. Raw data were subjected to various "cleaning" processes as described in Sect. 2 and then analyzed as described in this section. The time series subjected to data analysis includes 11910 time points covering 40 days of measurements (5317 time points in the fall and 5650 time points in the winter). This time series includes missing values of some variables, related to instrument failures or data filtering as described above. The length of the complete time series (i.e., with no missing value) varies from variable to variable (10897 time points for OA, 10361 time points for $\mathrm{NO}_{3}^{-}, 8999$ time points for $\mathrm{SO}_{4}^{2-}, 9677$ time points for $\mathrm{NH}_{4}^{+}$, 2656 time points for the PNSD, 2367 time points for AAE, $\mathrm{SSA}$, and $\mathrm{BC}, 1820$ time points for $f_{\mathrm{BC}}, f_{\mathrm{OA}}, f_{\mathrm{NO}_{3}}, f_{\mathrm{SO}_{4}}$, $f_{\mathrm{NH}_{4}}$, and OA-to-BC). Overall, about 1500 data points have the complete set of coincident measurements of all the variables addressed.

\subsection{Inference of the optical $\mathrm{BC}$ mass concentration}

The wavelength $(\lambda)$ dependent BC absorption coefficient $\left(\sigma_{\mathrm{aBC}}(\lambda)\right)$ and equivalent $\mathrm{BC}$ mass concentration were calculated using the $\mathrm{AAE}_{\mathrm{BC}}$ attribution method. The measured absorption coefficient at $660 \mathrm{~nm}\left(\sigma_{\mathrm{a}}(660)\right)$ was used to derive $\sigma_{\mathrm{aBC}}(530)$ and then the $\mathrm{BC}$ mass concentration, assuming (i) $\mathrm{BC}$ is the only light-absorbing species at $600 \mathrm{~nm}$, (ii) a known value of $\mathrm{AAE}_{\mathrm{BC}}$ at $530-660 \mathrm{~nm}$ (see below), and (iii) a BC mass absorption efficiency at $530 \mathrm{~nm}$ of $10 \mathrm{~m}^{2} \mathrm{~g}^{-1}$ (as indicated by PSAP manufacturer). In literature, $\mathrm{AAE}_{\mathrm{BC}}=1$ is a commonly used value for both externally mixed $\mathrm{BC}$ and internally mixed $\mathrm{BC}$. In fact, $\mathrm{AAE}_{\mathrm{BC}}$ for externally mixed $\mathrm{BC}$ was predicted to be 1 for particles with diameter $<50 \mathrm{~nm}$ (e.g., Bergstrom et al., 2002; Moosmüller et al., 2011) but can range from 0.8 to 1.1 for particle diameters of $50-200 \mathrm{~nm}$ (Gyawali et al., 2009). For ambient particles, which can be internally or externally mixed, $\mathrm{AAE}_{\mathrm{BC}}$ at visible wavelengths has often been observed to be larger than 1 (Lack and Langridge, 2013; Shinozuka et al., 2009, and references therein). Theoretical calculations have shown that the $\mathrm{AAE}_{\mathrm{BC}}$ for internally mixed $\mathrm{BC}$ can vary from 0.55 (e.g., Bahadur et al., 2012) to an upper limit of $\sim 1.7$ (e.g., Lack et al., 2008) depending on particle size, coating, core, and wavelength. In Fig. S2 of the Supplement we show numerically simulated (Mie theory) values of $\operatorname{AAE}\left(d_{\mathrm{p}}, \lambda, \mathrm{m}\right)$ resolved by particle diameter $\left(d_{\mathrm{p}}\right)$ and complex refractive index $(m(\lambda))$ at visible wavelengths $(\lambda)$ for $\mathrm{BC}$ (Sect. 3.4). It is shown that the AAE of BC tends to 1 for the smaller $\mathrm{BC}$ particles only and can differ significantly from 1 for the larger $B C$ particles. Based on these results and on previous works, we decided to use $\mathrm{AAE}_{\mathrm{BC}}=1.1$. The uncertainty $\delta\left(\mathrm{AAE}_{\mathrm{BC}}\right)$ was set to $22 \%\left(\frac{\delta\left(\mathrm{AAE}_{\mathrm{BC}}\right)}{\mathrm{AAE}_{\mathrm{BC}}}=0.22\right)$ according to Lack and Langridge (2013). BC uncertainty $(\delta(B C))$ was derived propagating this $\delta\left(\mathrm{AAE}_{\mathrm{BC}}\right)$ together with the uncertainty of PSAPderived $\sigma_{\mathrm{a}}$ (see Sect. 2.2).

We discarded data possibly affected by desert dust (43 records over 5 days of measurements) to ensure that the equivalent $\mathrm{BC}$ mass concentration is not affected by desert dust contamination (assumption (i) above). Dust-free aerosol conditions were identified based on the analysis of aerosol spectral optical properties, increasingly applied to gather information on aerosol type (e.g., Bergstrom et al., 2002; Shinozuka et al., 2009; Russell et al., 2010; Arola et al., 2011; Costabile et al., 2013). In particular, we followed the methodology proposed by Costabile et al. (2013) which identifies the aerosol dominated by dust by a distinctive combination of scattering and absorption Ångström exponents (SAE, AAE) and SSA spectral variation. Data points of the time series fulfilling this distinctive combination (indicated in Table 3 in Costabile et al., 2013) were excluded from the analysis.

\subsection{Fitting procedure for the PNSD}

PNSDs were measured by two different instruments (SMPS and APS, Sect. 2). These data were merged to obtain one PNSD based on particle electrical mobility diameters $\left(d_{\mathrm{m}}\right)$ ranging from $14 \mathrm{~nm}$ to $14 \mu \mathrm{m}$. PNSDs measured by APS are based on aerodynamic diameters $\left(d_{\mathrm{a}}\right)$; these data were converted to PNSDs based on $d_{\mathrm{m}}$ according to Eq. (2) (Khlystov et al., 2004; Seinfeld and Pandis, 2006):

$d_{\mathrm{m}}=\chi \frac{C_{\mathrm{c}}\left(d_{\mathrm{m}}\right)}{C_{\mathrm{c}}\left(d_{\mathrm{a}}\right)} \frac{d_{\mathrm{a}}}{\left(\frac{\rho_{\mathrm{p}}}{\rho_{0} \chi}\right)^{1 / 2}}$,

where $\chi$ is the shape factor, $C_{\mathrm{c}}\left(d_{\mathrm{m}}\right)$ and $C_{\mathrm{c}}\left(d_{\mathrm{a}}\right)$ are the slip correction factors based on $d_{\mathrm{m}}$ and $d_{\mathrm{a}}$, respectively, $\rho_{\mathrm{p}}$ is the particle density, and $\rho_{0}$ is the unit density $\left(1 \mathrm{~g} \mathrm{~cm}^{-3}\right)$. In applying Eq. (2) to convert APS data, we assumed that $d_{m}$ represents the true particle diameter, $C_{\mathrm{c}}\left(d_{\mathrm{m}}\right)=1$ and $C_{\mathrm{c}}\left(d_{\mathrm{a}}\right)=1$ 
(continuum regime), $\chi=1$ (spherical particles), and $\rho_{\mathrm{p}}$ continuously varies from 1.6 to $2 \mathrm{~g} \mathrm{~cm}^{-3}$.

PNSDs (i.e., $\left.n_{N}\left(\log _{10} d_{\mathrm{m}}\right)=\frac{\mathrm{d} N}{\operatorname{dlog}_{10}\left(d_{\mathrm{m}}\right)}\right)$ measured by SMPS and APS (PNSD ${ }_{\text {SMPS }}$, PNSD ${ }_{\text {APS }}$ ) overlap for $d_{\mathrm{m}}$ ranging from 460 to $593 \mathrm{~nm}$. In this size range, PNSD $_{S M P S}$ and PNSD $_{\mathrm{APS}}$ were replaced by $\mathrm{PNSD}_{\text {fitted. }}$ PNSD $\mathrm{P}_{\text {fitted }}$ was assumed to vary according to a power-law function (Junge size distribution) (Khlystov et al., 2004; Seinfeld and Pandis, 2006) (Eq. 3):

$n_{N}\left(\log _{10} d_{\mathrm{m}}\right)=\frac{c}{d_{\mathrm{m}}^{\alpha}}$.

The coefficients $c$ and $\alpha$ were calculated by an iterative procedure: (i) $c$ was randomly initialized from 0 to 1000 and (ii) $\alpha$ was calculated by Eq. (3) constraining values from 2 to 5 , as typically found for atmospheric aerosols (Seinfeld and Pandis, 2006). PNSD $_{\text {fitted }}$ replaced PNSD APS $_{\text {and }}$ PNSD $_{\text {SMPS }}$ when their relative difference ( $\delta$ (PNSD), Eq. 4 ),

$\delta(\mathrm{PNSD})=\frac{\left|\mathrm{PNSD}_{\mathrm{SMPS}}-\mathrm{PNSD}_{\mathrm{APS}}\right|}{\max \left[\mathrm{PNSD}_{\mathrm{SMPS}}, \mathrm{PNSD}_{\mathrm{APS}}\right]}$,

was larger than $0.1 \mathrm{~cm}^{-3}$. This procedure was considered acceptable if (i) the minimum mean squared error between

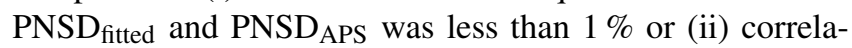
tion coefficients between PNSD $_{\text {fitted }}$ and PNSD SMPS $_{\text {and be- }}$ tween PNSD $_{\text {fitted }}$ and PNSD ${ }_{\text {APS }}$ were larger than 0.8 (98 of the records did not verify these conditions and were checked by visual inspection: 94 of them were discarded and 4 accepted). The final dataset contained PNSD data based on $d_{\mathrm{m}}$ from 14.1 to $429.4 \mathrm{~nm}$ measured by the SMPS, from 446.1 to $699 \mathrm{~nm}$ generated by the fitting procedure, and from 0.7 to $14 \mu \mathrm{m}$ measured by the APS. The particle surface size distribution (PSSD, i.e., $\left.n_{S}\left(\log _{10} d_{\mathrm{m}}\right)=\frac{\mathrm{d} S}{\operatorname{dlog}_{10}\left(d_{\mathrm{m}}\right)}\right)$ and particle volume size distribution (PVSD, i.e., $n_{V}\left(\log _{10} d_{\mathrm{m}}\right)=$ $\left.\frac{\mathrm{d} V}{\operatorname{dlog}_{10}\left(d_{\mathrm{m}}\right)}\right)$ were calculated from this PNSD under the hypotheses of spherical particles (Hinds, 1999; Seinfeld and Pandis, 2006).

\subsection{Principal component analysis (PCA) of PNSD}

PNSDs were statistically analyzed through PCA to identify key aerosol types with known modality. The relevant methodology was described in a previous study by Costabile et al. (2009). In short, principal components (PCs) retained in the analysis were arranged in decreasing order of variance explained $\left(\varkappa_{k}\right.$, called eigenvalue of $\left.\mathrm{PC}_{k}\right), \mathrm{PC} 1$ being the component explaining the largest $\varkappa_{k}$. The $k$ th eigenvector is composed of scalar coefficients describing the new $\mathrm{PC}_{k}$ as a linear combination of the original variables (the original variables are the time series of $\left.\mathrm{d} N / \mathrm{d} \log \left(d_{\mathrm{p}}\right)\right)$. Factor loadings of $\mathrm{PC}_{k}$ represent the relative weight of the original variables in the $\mathrm{PC}_{k}$ re-scaled. Loadings thus show the "mode" of the PNSD associated with the PCs. Factor scores of $\mathrm{PC}_{k}$ represent the time series of $\mathrm{PC}_{k}$ values in the new coordinates of the space defined by the PCs. Scores thus represent the $\mathrm{PC}_{k}$ values in the time series of the original variables.

PCA retained three principal components (PC1-PC3) explaining approximately $80 \%$ of the variance. Factor loadings and diurnal cycles of scores for PC1-PC3 are illustrated in Fig. S3 of the Supplement, while Pearson's correlation coefficients $r$ between these PCs and the other variables measured are shown in Table 1. Tables 1 and S2 of the Supplement show relevant $r$ values in the winter and in the fall and relevant Bonferroni adjusted probabilities ( $p$ values), respectively. These PCs were interpreted as follows:

- PC1 is the largest component in terms of variance explained $(51 \%)$. Loadings peak in the $80-300 \mathrm{~nm}$ size range. Factor scores correlate to $\mathrm{OA}$ and $\mathrm{BC}$. Weekly diurnal cycles of these scores are higher on working days and in the road-traffic rush hour. This PC represents the aerosol enriched in OA originating in the traffic rush hour in the urban area due to local emissions (e.g., Costabile et al., 2009; Brines et al., 2015, and references therein).

- PC2 explains $14 \%$ of the variance. Loadings peak in the ultrafine size range (approx. $100 \mathrm{~nm}$ ). Factor scores show diurnal cycles higher at night and in the winter, with a slightly larger contribution during the weekends. It correlates (inversely) to aerosol size and (directly) to $f_{\mathrm{OA}}$; in the winter it correlates to both $f_{\mathrm{OA}}$ and $f_{\mathrm{BC}}$ (0.40, $p<0.001$; Table S1 of the Supplement). This PC should represent the nocturnal urban aerosol related to residential heating emissions.

- PC3 explains $13 \%$ of the variance. Loadings peak in the larger accumulation-mode size range (from 0.3 to $1 \mu \mathrm{m})$. Diurnal cycles of scores are higher in daytime. It is inversely correlated to $f_{\mathrm{BC}}$ and directly to nitrate, sulfate, and ammonium. This PC represents the dropletmode aerosol poor in $\mathrm{BC}$, previously found to originate in fog droplets, cloud droplets, and wet aerosol particles, due to aqueous-phase processing (John, 1990; Meng and Seinfield, 1994; Seinfeld and Pandis, 2006; Ervens et al., 2011).

\subsection{Numerical simulations of $\mathrm{AAE}$}

Values of $\operatorname{AAE}\left(d_{\mathrm{p}}, \lambda, \mathrm{m}\right)$ resolved by diameter $d_{\mathrm{p}}$, radiation wavelength $(\lambda)$, and complex refractive index $\left(m_{(\lambda)}=\right.$ $\left.n_{(\lambda)}-i k_{(\lambda)}\right)$ were numerically simulated according to Mie theory (e.g., Bohren and Huffman, 1983; Moosmüller et al., 2011). The aim was to reproduce patterns expected for $\mathrm{BrC}$, $\mathrm{BC}$, and the urban background aerosol impacted by biomassburning emissions, as these were abundant in the study area. Simulations are illustrated in Fig. S2 of the Supplement, the relevant methodology being described in a previous study by Costabile et al. (2013).

To simulate patterns expected for $\mathrm{BrC}$ in the urban ambient aerosol, we used $\lambda$ dependent complex values of $m_{(\lambda)}$ in- 
Table 1. Statistically significant $(p<0.001)$ Pearson's correlation coefficients $(r)$ between absorption Ångström exponent (AAE) at 467$660 \mathrm{~nm}$; scores of major aerosol types identified by PCA (PC1 is the road-traffic-related aerosol, PC2 is the residential heating related aerosol, and PC3 is the droplet-mode aerosol); mass concentration and mass fractions $\left(f_{x}\right)$ of black carbon $(\mathrm{BC})$, organics $(\mathrm{OA})$, nitrate $\left(\mathrm{NO}_{3}^{-}\right)$, sulfate $\left(\mathrm{SO}_{4}^{2-}\right)$, and ammonium $\left(\mathrm{NH}_{4}^{+}\right)$; optically relevant aerosol size representative of the entire aerosol population (calculated as median mobility diameter of the particle surface size distribution, $d_{\operatorname{med}(S)}$ ); OA-to-BC ratios (see Tables S1 and S2 of the Supplement for additional relevant values).

\begin{tabular}{|c|c|c|c|c|c|c|c|c|c|c|c|c|c|}
\hline $\mathrm{r}$ & AAE & $d_{\operatorname{med}(S)}$ & $\mathrm{BC}$ & $f_{\mathrm{BC}}$ & OA & $f_{\mathrm{OA}}$ & OA-to-BC & $\mathrm{NO}_{3}$ & $f_{\mathrm{NO}_{3}}$ & $\mathrm{SO}_{4}$ & $f_{\mathrm{SO}_{4}}$ & $\mathrm{NH}_{4}$ & $f_{\mathrm{NH}_{4}}$ \\
\hline$d_{\operatorname{med}(S)}$ & 0.60 & 1 & -0.24 & -0.38 & - & -0.68 & 0.37 & 0.48 & 0.50 & 0.30 & 0.25 & 0.49 & 0.69 \\
\hline AAE & 1 & 0.60 & -0.26 & -0.52 & 0.40 & -0.34 & 0.78 & 0.60 & 0.40 & 0.67 & 0.18 & 0.65 & 0.44 \\
\hline $\mathrm{PC} 1$ & - & - & 0.56 & - & 0.83 & - & - & 0.52 & - & - & - & 0.52 & - \\
\hline PC2 & - & -0.52 & - & - & - & 0.31 & - & -0.19 & - & - & - & -0.20 & -0.27 \\
\hline PC3 & 0.66 & 0.60 & -0.38 & -0.53 & 0.12 & -0.52 & 0.54 & 0.46 & 0.50 & 0.45 & - & 0.49 & 0.58 \\
\hline
\end{tabular}

ferred during CAPMEX for an air mass with $\mathrm{AAE}_{405-532}=$ 3.8 (standard deviation $=3.4$ ), characterized by high $\mathrm{OC}$ to sulfate $\left(\mathrm{SO}_{4}^{2-}\right)$ ratio and high nitrate $\left(\mathrm{NO}_{3}^{-}\right)$to $\mathrm{SO}_{4}^{2-}$ ratio (Flowers et al., 2010; Moise et al., 2015). These are $m_{467}=1.492-0.026 i, m_{530}=1.492-0.017 i$, and $m_{660}=$ $1.492-0.014 i$, the uncertainty for $n_{(\lambda)}$ and $k_{(\lambda)}$ being set to \pm 0.01 and \pm 0.001 , respectively.

To simulate patterns expected for BC we used $\lambda$ independent complex values of $m$ estimated by Alexander et al. (2008) for soot carbon particles at $550 \mathrm{~nm}: n=1.95-0.79 i$ at $\lambda=467,530,660 \mathrm{~nm}$. Note in Fig. S2 of the Supplement the resulting variability with $d_{p}$ of $A_{A E_{467-660}}$ for BC: values of $\mathrm{AAE}=1$ are only obtained for $d_{\mathrm{p}} \ll 100 \mathrm{~nm}$.

To simulate patterns expected for the urban background aerosol impacted by biomass-burning emissions we used values of $m_{(\lambda)}$ inferred in a previous study for the smaller accumulation-mode particles enriched in BC from biomassburning smoke (Costabile et al., 2013): $m_{467}=1.512$ $0.027 i, m_{530}=1.510-0.021 i$, and $m_{660}=1.511-0.022 i$, the uncertainty for $n_{(\lambda)}$ and $k_{(\lambda)}$ being set to \pm 0.01 and \pm 0.001 , respectively.

\section{Results and discussion}

In this section we first identify $\mathrm{BrC}$ and characterize its optical-microphysical-chemical properties (Sect. 4.1), then illustrate a case study (Sect. 4.2), and finally discuss the findings in comparison with the literature (Sect. 4.3).

\subsection{Brown carbon: identification and features}

Several literature studies identify $\mathrm{BrC}$ based on the high AAE values in the bulk aerosol, i.e., from 2 to 6 (e.g., Andreae and Gelencsér, 2006; Bond et al., 2013). At a certain range of wavelengths $(\lambda)$, these high AAE values depend on several factors, including aerosol size, chemical composition, and aerosol mixing state. First, we analyzed the dependence of AAE on aerosol size. We used two different approaches. We calculated the median mobility diameter of the PSSD (Sect. 3.2) $-d_{\operatorname{med}(S)}$ - to obtain the optically relevant aerosol size representative of the entire particle population. We then analyzed the PNSD to find major aerosol types (i.e., PCs; Sect. 3.3). We found two components (PC1 and $\mathrm{PC} 2)$ related to smaller particles and originating from local emissions (road traffic and residential heating, respectively), and one component (PC3) related to larger particles (droplet mode) originating from the aerosol processing. Second, we analyzed the relation between AAE, these PCs, and $d_{\operatorname{med}(S)}$ and related these to $\mathrm{PM}_{1}$ major constituents. Relevant statistically significant Pearson's correlation coefficients $(r)$ are shown in Table 1, while $r$ values observed in the winter and in the fall and the matrix of Bonferroni probabilities $(p)$ associated with these $r$ values are shown in Tables S1 and S2 of the Supplement.

The AAE correlates well with the $d_{\operatorname{med}(S)}$ of the aerosol population $(r=0.60, p<0.001)$. In Fig. 1 we analyze this relation by comparing field measurements to numerical simulations results (these simulations are based on the Mie theory and are described in detail in Sect. 3.4). Measurements show that the AAE increases with the increase of the $d_{\operatorname{med}(S)}$ (grey markers). We show the $\mathrm{AAE}$ and $d_{\operatorname{med}(S)}$ representative of the three different aerosol types identified (PC1, PC2, and PC3). To interpret these measurements we add patterns theoretically expected (through numerical simulations) for three aerosol types: $\mathrm{BrC}$ in the ambient aerosol (brown line), a pure BC particle (black line), and an urban background aerosol impacted by wood-burning emissions (grey line). The lowest AAEs measured in the present study tend to values expected for pure BC (black line), but they are similar to values calculated for the urban background aerosol impacted by woodburning emissions (grey line) - both aerosol types which were related to local emissions ( $\mathrm{PC} 1$ and $\mathrm{PC} 2)$ match these patterns. Larger AAEs (3.2 \pm 0.9$)$ correspond to the dropletmode aerosol (PC3) and are similar to the AAE expected for $\mathrm{BrC}$ (brown line). Note that Fig. 1 suggests that the threshold value of $\mathrm{AAE}_{467-660}$ distinguishing $\mathrm{BrC}$ is $\mathrm{AAE}>2.3$.

The dotted black line in Fig. 1 represents the best fit to all the data points of the measurements. This line shows 


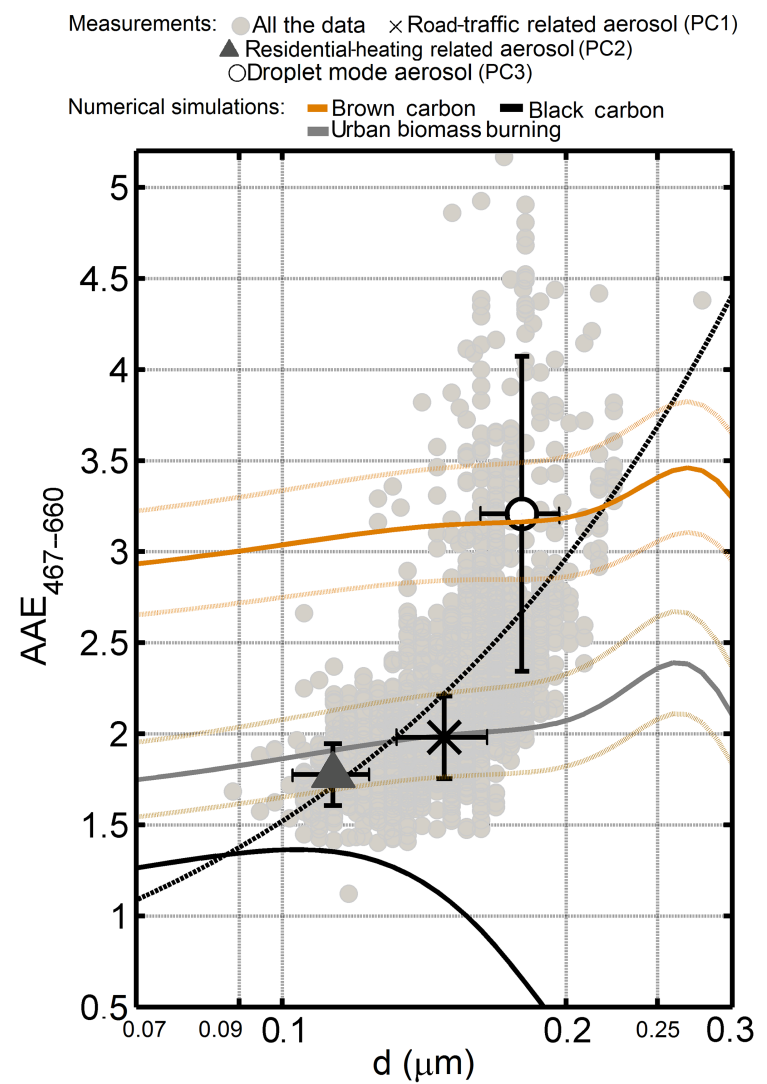

Figure 1. Experimentally measured and numerically simulated (Mie theory) relation between absorption Ångström exponent (AAE) at 467-660 nm and aerosol size $(d)$. For measurements, (i) $d$ is represented by the mobility median diameter of the $\mathrm{PM}_{10}$ particle surface size distribution $\left(d_{\operatorname{med}(S)}\right)$; (ii) all the data measured are indicated by light grey markers, the dotted black line representing the best fit to these data; (iii) major aerosol types identified (Sect. 3.3) are indicated by darker markers (median \pm standard deviation). For numerical simulations (Sect. 3.4), patterns theoretically expected for $\mathrm{BrC}, \mathrm{BC}$, and urban biomass burning are indicated by brown, black, and grey thick lines, respectively, the dotted thinner lines indicating the uncertainty of the refractive index $\left(m_{(\lambda)}=n_{(\lambda)}-i k_{(\lambda)}\right)$ set to \pm 0.01 for $n_{(\lambda)}$ and \pm 0.001 for $\left.k_{(\lambda)}\right)$.

the increase of the AAE with the increase of the $d_{\operatorname{med}(S)}$ in the measurements. To interpret this pattern, we note that the brown and grey lines (referring to the simulations of $\mathrm{BrC}$ and of the wood-burning-related aerosol, respectively) show the theoretical increase of the AAE with increasing only the aerosol size - i.e., when $m_{(\lambda)}$ is constant. Comparing these three lines, it is evident that specific values of $m_{(\lambda)}$ are necessary in addition to a proper particle size range to match the large AAE measured for the dropletmode $\mathrm{BrC}$ aerosol. These values are $k_{(467)}=0.026 \pm 0.001$, $k_{(530)}=0.017 \pm 0.001, k_{(660)}=0.014 \pm 0.001$, and $n_{467}=$ $1.47 \pm 0.01$ (Sect. 3.4). These are $\lambda$ dependent values consistent with $\mathrm{BrC}$ in the ambient atmosphere (Moise et al., 2015 ) in an air mass with high $\mathrm{OC}$ to $\mathrm{SO}_{4}^{2-}$ ratio and $\mathrm{NO}_{3}^{-}$
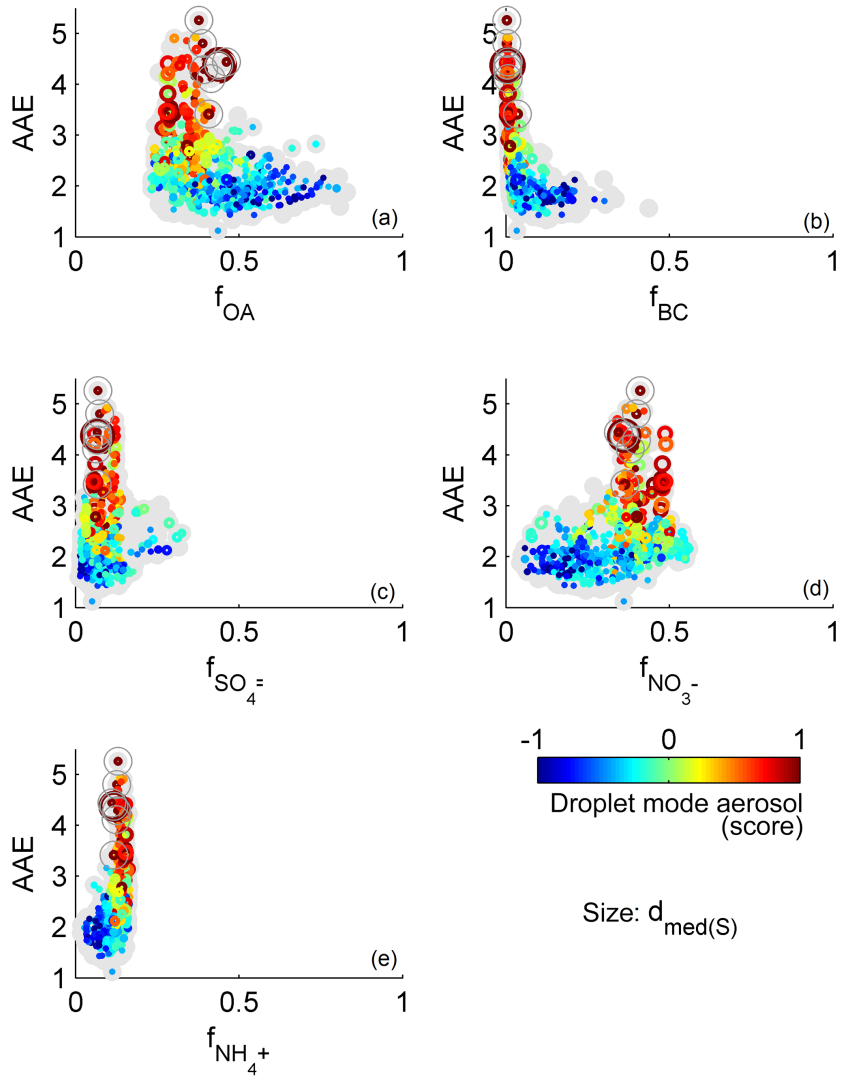

Size: $d_{\operatorname{med}(S)}$

Figure 2. Physicochemical features of brown carbon. Absorption Ångström exponent at 467-660 nm (AAE) plotted against mass fractions $\left(f_{x}\right)$ of (a) organic aerosol (OA), (b) black carbon (BC), (c) sulfate $\left(\mathrm{SO}_{4}^{2-}\right)$, (d) nitrate $\left(\mathrm{NO}_{3}^{-}\right)$, and (e) ammonium $\left(\mathrm{NH}_{4}^{+}\right)$. Grey markers show the longest available time series for AAE and $f_{x}$, while marker color and size indicate data points for which the droplet-mode aerosol scores and $d_{\operatorname{med}(S)}$ were available (Sect. 3). Data indicated by dark grey "o" show case study values illustrated in Fig. 4.

to $\mathrm{SO}_{4}^{2-}$ ratio (Flowers et al., 2010). This finding emphasizes that $\mathrm{BrC}$ properties depend on both aerosol size distribution and chemical composition (i.e., $\left.m_{(\lambda)}\right)$.

Figure 2 investigates the link between chemical, microphysical, and optical properties. AAE is plotted against $\mathrm{PM}_{1}$ major chemical components $(\mathrm{OA}, \mathrm{BC}$, nitrate, sulfates, and ammonium $\mathrm{PM}_{1}$ mass fractions, $f_{x}$ ). Grey markers show the longest available time series for AAE and $f_{x}$, while colored markers show the data points for which the droplet-mode aerosol scores (marker color) and the $d_{\text {med(S) }}$ (markers size) were available (see Sect. 3 ). The BrC aerosol population (identified by AAE $>2.3$ ) shows higher $f_{\mathrm{NO}_{3}}$ and $f_{\mathrm{NH}_{4}}$ and lower $f_{\mathrm{BC}}$ values coupled to larger $d_{\text {med }(S)}$ and high droplet-mode aerosol scores. Relevant average values are as follows (mean \pm standard deviation): $\mathrm{AAE}=3.2 \pm 0.9, \quad f_{\mathrm{NO}_{3}}=0.38 \pm 0.05, \quad f_{\mathrm{BC}}=0.01 \pm 0.01$, $f_{\mathrm{OA}}=0.35 \pm 0.04, f_{\mathrm{SO}_{4}}=0.1 \pm 0.02, f_{\mathrm{NH}_{4}}=0.14 \pm 0.01$, 
and $\mathrm{SSA}_{530}=0.98 \pm 0.01$ (and $\sigma_{\mathrm{a} 467}=7.6 \pm 3.33 \mathrm{Mm}^{-1}$, $\sigma_{\mathrm{s} 467}=312 \pm 64 \mathrm{Mm}^{-1}$, and $\left.\mathrm{SAE}=0.5 \pm 0.4\right)$. The relation between AAE and SSA will be further analyzed in Fig. 5 (in Fig. S4 of the Supplement we show the relation between the droplet-mode aerosol and SSA).

Both Fig. 2 and Table 1 show no direct correlation between AAE and $f_{\mathrm{OA}}$. This may be explained by the fact that AAE correlates with larger particles (larger $\left.d_{\operatorname{med}(S)}\right)$ of the droplet mode (larger PC3 scores), while the $f_{\mathrm{OA}}$ correlates with smaller particles (lower $d_{\operatorname{med}(S)}$ ) from residential heating emissions (larger PC2 scores). There is instead a significant correlation between $\mathrm{AAE}$ and the ratio of OA to $\mathrm{BC}(r=0.78, p<0.001)$, a variable indicating either combustion characteristics (higher for biofuels than for fossil fuel combustion) or aerosol ageing (lower for fresh aerosols) (Saleh et al., 2014; Bond et al., 2013). The increase of the AAE with the decrease of the BC-to-OA ratios is illustrated in Fig. 3. Light-grey markers show the longest available time series for AAE and BC-to-OA ratios, while colored markers correspond to data points for which the droplet-mode aerosol scores and $f_{\mathrm{NO}_{3}}$ were available. The relation observed between $\mathrm{AAE}$ and $\mathrm{BC}$-to-OA is an average aerosol property (i.e., for both $\mathrm{BC}$ and $\mathrm{OA}$ ) as suggested by the parametrization of AAE as a function of the BC-to-OA ratio (inner panel of Fig. 3) consistent with Lu et al. (2015) (see Sect. 4.3). The grey line (referring to all the data points) shows the parametrization for the bulk aerosol. The black line (referring to the subset of all the data with PC3 scores $>0$ ) shows the parametrization for $\mathrm{BrC}$. We note a larger dependence of $\mathrm{AAE}$ on the BC-to-OA ratio for $\mathrm{BrC}(r=-0.86, p<0.001)$ - as opposed to the bulk aerosol $(r=-0.7, p<0.001)$. However, this can be due to the fact that at low BC-to-OA ratios OA has more weight in dictating AAE.

In Fig. 3 AAE plateaus at values higher than 1 for large $\mathrm{BC}$-to-OA ratios. We acknowledge that $\mathrm{BC}$ and $\mathrm{AAE}$ derived from PSAP measurements are affected by uncertainty related to the assumption employed to convert raw PSAP measurements to absorption coefficients, which is about $\pm 40 \%$ based on literature studies (Lack et al., 2008; Nakayama et al., 2010; Lack and Langridge, 2013; Bond et al., 2013; Backman et al., 2014). This uncertainty could in principle reconcile our plateau AAE values higher than 1 with the common assumption that AAE tends to 1 when the aerosol is dominated by BC. Nevertheless, we modeled AAE as a function of aerosol chemical and microphysical properties (Fig. 1). Such simulation clearly shows that AAE close to 1 can be obtained for aerosol population dominated by fresh fossil fuel combustion emissions, with diameter centered below $20 \mathrm{~nm}$. Conversely the size distribution of aerosol population investigated in this study is centered around $80-300 \mathrm{~nm}$ (Fig. 1). In addition, source apportionment studies performed in the Po valley show that carbonaceous aerosol, both in urban and rural sites, is strongly affected by wood-burning emissions (Gilardoni et al., 2011; Larsen et al., 2012; Gilardoni et al., 2016). It follows that, even considering the possible bias due

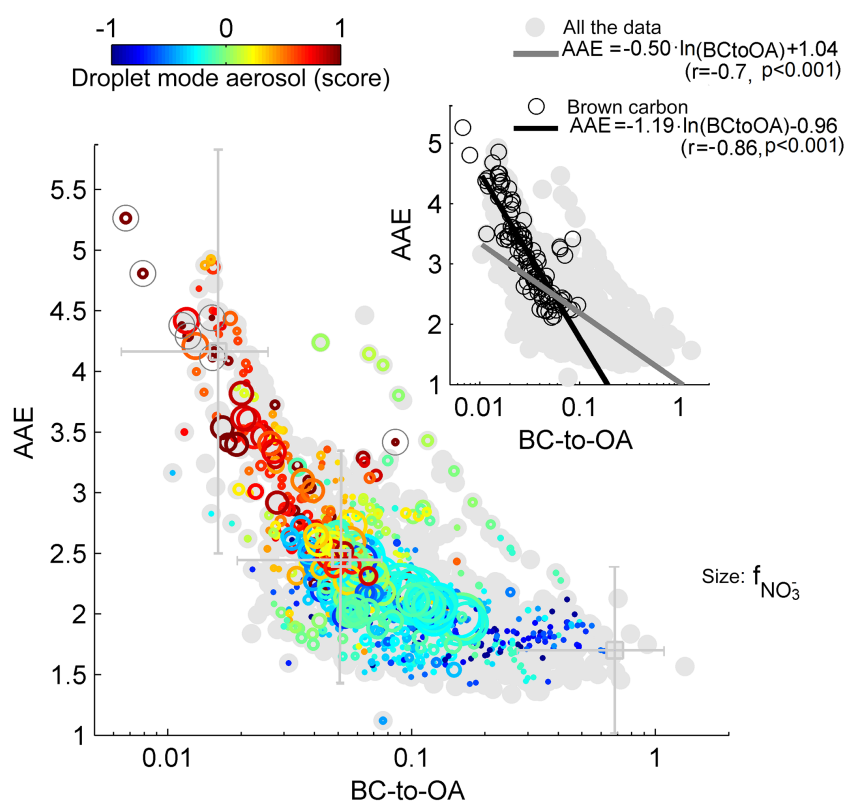

Figure 3. Dependence of AAE on BC-to-OA ratios. Grey markers show the longest available time series for AAE at $467-660 \mathrm{~nm}$ and $\mathrm{BC}$-to-OA ratios, while marker color and size indicate data points for which the droplet-mode aerosol scores and $f_{\mathrm{NO}_{3}}$ were available (Sect. 3). Median values (grey squares) and relevant data uncertainty are indicated at the upper, mean, and lower AAE bins. Data indicated by dark grey "o" show case study values illustrated in Fig. 4. Inner panel: best fit lines with relevant equation and Pearson's correlation coefficients $(r, p)$ to all the data measured (grey line) and droplet-mode $\mathrm{BrC}$ data (black line) (as indicated by droplet-mode aerosol score $>0$ ).

to the experimental uncertainty, the AAE plateauing at values higher than 1 for large BC-to-OA ratios is still is in agreement with model results and source apportionment data.

Taken together, these findings prove that $\mathrm{BrC}$ in the observed ambient aerosol shows $\mathrm{AAE}_{467-660}=3.2 \pm 0.9$ with $k_{(530)}=0.017 \pm 0.001$ and occurs in particles in the dropletmode size range, enriched in ammonium nitrate and poor in $\mathrm{BC}$, with a strong dependance on OA-to-BC ratios, $\mathrm{SSA}_{530}$ being $0.98 \pm 0.01$. In particular, when the bulk aerosol is dominated by the $\mathrm{BrC}$ droplet-mode particles, the AAE is greater than $2.3 \pm 1$ (median \pm uncertainty), and BC-to-OA ratios are lower than $0.05 \pm 0.03$.

\subsection{A case study}

We present here a case study (Fig. 4) to show the main microphysical and chemical features of the $\mathrm{BrC}$ aerosol observed.

On the case study day (i.e., 1 February 2013) the relative humidity was high $(97.5 \pm 0.4 \%$, against a mean value for the winter campaign of $82 \pm 14 \%$, and a maximum of $98 \%$ ), temperature averaged $2.8 \pm 0.0^{\circ} \mathrm{C}$ (campaign mean value $=3.5 \pm 2.8^{\circ} \mathrm{C}$ ), and aerosol liquid water content was above $200 \mu^{-3} \mathrm{~m}^{-3}$ (Gilardoni et al., 2016). Absorption and 

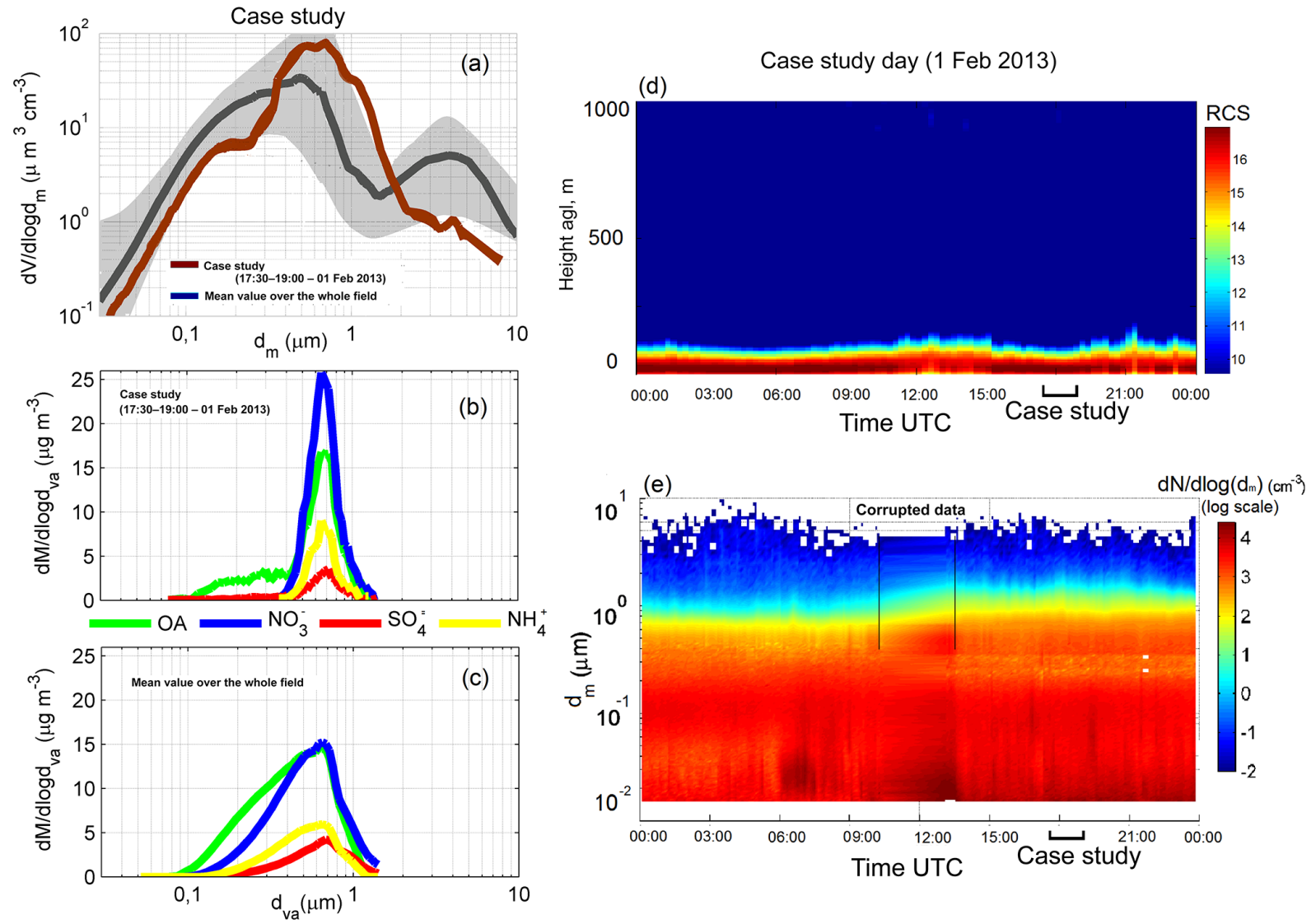

Figure 4. A case study illustrating BrC major features. Case study time period (1.5 h) is from 17:30 to 19:00 UTC on 1 February 2013 (local time at the Po Valley sampling site in this period is UTC $+1 \mathrm{~h}$ ). Case study values are compared with mean values over the whole field experiment. Panels illustrate (a) particle volume size distribution $\left(\mathrm{d} V / \mathrm{dlog}_{10} d_{\mathrm{m}}\right.$, based on electrical mobility particle diameter $\left.d_{\mathrm{m}}\right)$ during the case study and relevant mean values; (b) particle mass size distribution ( $\mathrm{d} M / \mathrm{dlog}_{10} d_{\mathrm{va}}$, based on vacuum aerodynamic diameter, $\left.d_{\mathrm{va}}\right)$ during the case study; (c) relevant mean values; (d) aerosol vertical profiles in the atmosphere during the entire case study day (time-height cross section of the range corrected signal, $\mathrm{RCS}=\ln \left(S \times R^{2}\right)$, from an LD40 ceilometer); (e) particle number size distributions during the entire case study day.

scattering coefficients at $530 \mathrm{~nm}$ (Fig. S1 of the Supplement) ranged from 5 to $10 \mathrm{Mm}^{-1}$ (with larger AAE) and from 300 to $400 \mathrm{Mm}^{-1}$ (with lower SAE), respectively, with SSA $530=$ $0.98 \pm 0.01$. The number concentration of $2-10 \mu \mathrm{m}$ particles (Fig. 4e) had a peak at approx. 04:00 UTC (we interpret this as particle growth by water vapor) and then decreased until 09:00 UTC. After this, the number concentration of $0.3-1 \mu \mathrm{m}$ particles increased. This increase occurred just after the part of the day (from 11:00 to 14:00) when the strong signal in the aerosol vertical profile at the ground (the darker red layer in Fig. 4d) is observed to dissipate (we interpret this as droplet evaporation). These processes are consistent with the formation of the droplet-mode aerosol (John, 1990; Meng and Seinfield, 1994; Seinfeld and Pandis, 2006) explaining the increase of the droplet-mode aerosol scores (PC3) observed in the afternoon. The case study was selected during this period (1.5 $\mathrm{h}$ from 17:30 to 19:00), and relevant data are shown in
Figs. 2, 3, 5, and S1 of the Supplement (in this figure, the case study is the first day of the winter field campaign).

During the case study (i.e., from 17:30 to 19:00 on 1 February 2013) we observed peculiar data. The AAE was significantly higher (3.4-5.3) than the median value $(2.0 \pm 0.5$ during both field campaigns and $2.1 \pm 0.6$ in the winter). The volume size distribution (Fig. 4a) was narrow and monomodal, centered on the droplet mode $\left(d_{\mathrm{m}}\right.$ from 450 to $700 \mathrm{~nm}$ ). Relevant mass size distributions of the main constituents of $\mathrm{nr}-\mathrm{PM}_{1}\left(\mathrm{NO}_{3}^{-}, \mathrm{OA}\right.$, and $\left.\mathrm{NH}_{4}^{+}\right)$were centered around $700 \mathrm{~nm}$ of the vacuum aerodynamic diameter $\left(d_{\mathrm{va}}\right)$, corresponding to about $500 \mathrm{~nm}$ in mobility diameter (for spherical particles in the continuum regime with $\rho_{\mathrm{p}}=1.4 \mathrm{~g} \mathrm{~cm}^{-3}$; Seinfeld and Pandis, 2006). In addition, the OA mass below $d_{\mathrm{va}}=300 \mathrm{~nm}$ was significantly lower than that of the droplet mode, especially when compared to the average field results (Fig. 4c). It is important to note that the collection efficiency of the HR-ToF-AMS is $50 \%$ for $600 \mathrm{~nm}$ 

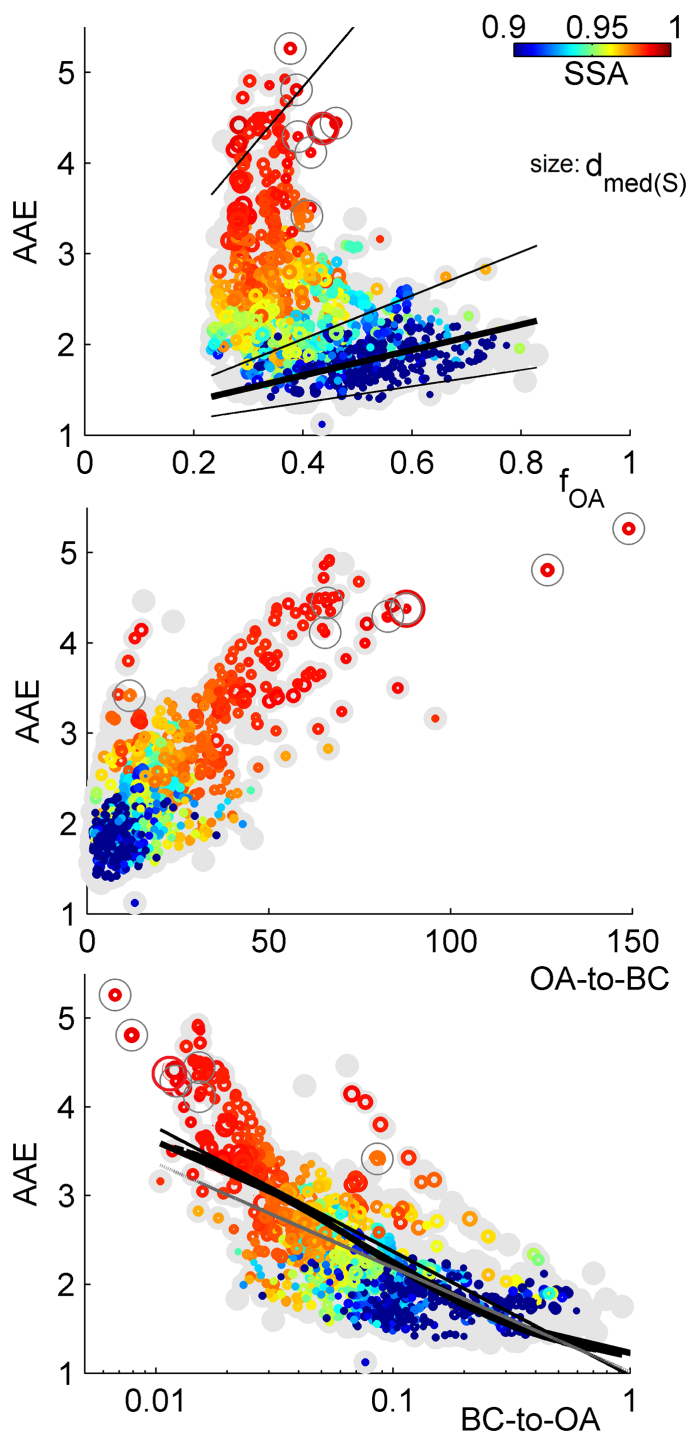

Figure 5. Absorption Ångström exponent at 467-660 nm (AAE) against: (a) OA mass fraction, (b) OA-to-BC ratios, and (c) BC-to$\mathrm{OA}$ ratios. Grey markers show the longest available time series for $\mathrm{AAE}$ and $f_{\mathrm{OA}}$, while colored markers show data points for which the SSA at $530 \mathrm{~nm}$ and $d_{\text {med }_{S}}$ were available (Sect. 3). Best fit lines to data taken from (i) Shinozuka et al. (2009) (at different SSA bins, i.e., 0.98-1.00, 0.96-0.98, 0.90-0.92, from top to bottom) and Russell et al. (2010) are indicated in panel (a) (thin and thick black lines, respectively); (ii) Saleh et al. (2014) and Lu et al. (2015) are indicated in panel (c) (black thick and thin lines, respectively); (iii) this work is indicated in panel (c) (grey line, as in Fig. 3). Data indicated by dark grey "o" show case study values illustrated in Fig. 4.

particles and decreases for larger sizes (Liu et al., 2007). This explains the difference between the size distributions in Fig. $4 a$ and $b$ at larger sizes.

At the light of source apportionment study performed on organic aerosol (Gilardoni et al., 2016) we explain the increase of AAE during the case study period with the forma- tion of secondary organic aerosol in the aqueous phase associated with aerosol particles. The analysis of microphysical properties reported in this study confirms that the aqueous secondary organic aerosol formation adds mass to the atmospheric aerosol in the droplet-mode range. This case study both illustrates and confirms general features observed for $\mathrm{BrC}$ during the whole field campaign.

\subsection{Discussion in comparison with previous works}

In this section we discuss our findings and explore their consistency with the literature.

The analysis of chemical and microphysical properties shows that $\mathrm{BrC}$ associated with the formation of secondary aerosol has a narrow monomodal size distribution centered around the droplet mode $(400-700 \mathrm{~nm})$ in the entire $\mathrm{PM}_{10}$ size range. This result agrees with the observations reported by Lin et al. (2010), showing that $80 \%$ of the mass of atmospheric humic-like substances, a light-absorbing organic aerosol component, was found in the droplet mode. The correspondence between $\mathrm{BrC}$ and the droplet-mode aerosol points to the important role that aqueous reactions within aerosol particles can play in the formation of light-absorbing organic aerosol (Ervens et al., 2011; Laskin et al., 2015).

The study of optical and chemical properties indicates that in our case the larger AAE values associated with $\mathrm{BrC}$ depend on the organic fraction in a different way from that in literature (Shinozuka et al., 2009; Russell et al., 2010; Arola et al., 2011). In Fig. 5a we compare our measurements collected at the urban background site of Bologna with the trend previously found based on airborne and sun photometers observations (Shinozuka et al., 2009; Russell et al., 2010). AAE is plotted versus the mass fraction of organic aerosol $\left(f_{\mathrm{OA}}\right)$, the marker color being SSA 530 as in Fig. 7 in Shinozuka et al. (2009). We show the best fit lines (thin black lines) identified by Shinozuka et al. (2009) and corresponding to different SSA bins, and the best fit reported by Russell et al. (2010) (thick black line). Note that the larger AAE values in our study (associated with $\mathrm{BrC}$ in the droplet mode) correspond to the fit line in Shinozuka et al. (2009) at SSA $=0.98-1$ but were associated with lower scattering coefficients in those previous studies. There is consistency between our study and those reported previously. However, our data show that increasing AAE is accompanied by increasing the OA normalized to BC (Fig. 5b, $r=0.78, p<0.001$ ) rather than by increasing OA (Fig. 5a). This comparison adds to the literature that for the ambient aerosol in the lower troposphere AAE correlates with OA-to-BC ratios far more than with the organic fraction.

We found that $\mathrm{BrC}$ corresponds to $\mathrm{BC}$-to-OA ratios below $0.05 \pm 0.03$. Figure $5 \mathrm{c}$ shows the dependence of AAE on the BC-to-OA ratio as parametrized by Saleh et al. (2014) and Lu et al. (2015) for biomass-burning emissions and primary organic aerosol emissions. The best fit line to measurements performed in this study (grey line) is similar to the 
fitting lines reported previously (thicker and thinner black lines, showing respectively data from Saleh et al., 2014 and $\mathrm{Lu}$ et al., 2015). While we cannot compare absolute values because we compare the AAE of the bulk aerosol (this study) to the AAE of OA only (Saleh et al., 2014; Lu et al., 2015), it is evident that patterns are similar. This comparison extends the dependence of AAE on BC-to-OA observed in chamber experiments (solely for fresh biomass-burning primary OA and not for fossil fuel OA) by Saleh et al. (2014) and Lu et al. (2015) to ambient aerosol dominated by wood-burning emissions (Gilardoni et al., 2016).

\section{Summary and conclusions}

We investigated optical-chemical-microphysical properties of $\mathrm{BrC}$ in the urban ambient atmosphere. In situ ground measurements of chemical (HR-ToF-AMS), optical ( $3 \lambda$ nephelometer and PSAP), and microphysical (SMPS and APS) aerosol properties were carried out in the Po Valley (Bologna), together with ancillary observations. BrC was identified and characterized by linking the wavelength dependence of light absorption (as indicated by the AAE) in the visible region to key aerosol types with known size distributions, and to major $\mathrm{PM}_{1}$ chemical components (BC, OA, nitrate, ammonium, and sulfate). $\mathrm{BrC}$ measurements were interpreted through numerical simulations (Mie theory) of $\operatorname{AAE}\left(d_{\mathrm{p}}, \lambda, \mathrm{m}\right)$ resolved by particle size $\left(d_{\mathrm{p}}\right)$ and wavelength $(\lambda)$ dependent complex refractive index $\left(m_{(\lambda)}=n_{(\lambda)}-i k_{(\lambda)}\right)$ in the visible region.

We found the following:

1. AAE increases with increasing the (optically relevant) aerosol size. Larger AAEs ( $3.2 \pm 0.9$, with values up to 5.5) occur when the bulk aerosol size distribution is dominated by the droplet mode, i.e., the large accumulation mode originating from the aerosol processing in the aqueous phase. These values identify $\mathrm{BrC}$.

2. Specific $m_{(\lambda)}$ values are necessary in addition to a proper particle size range to match the high $\mathrm{AAE}$ measured for $\mathrm{BrC}$. These $m_{(\lambda)}$ values are theoretically expected to be $k_{(467)}=0.026 \pm 0.001$, $k_{(530)}=0.017 \pm 0.001, \quad k_{(660)}=0.014 \pm 0.001, \quad$ and $n_{467}=1.47 \pm 0.01\left(\mathrm{SSA}_{530}=0.98 \pm 0.01\right)$, consistent with literature $m_{(\lambda)}$ values for $\mathrm{BrC}$ in the ambient atmosphere.

3. AAE increases with increasing the OA-to-BC ratio, rather than with increasing $f_{\mathrm{OA}}$, the larger AAEs (and thus $\mathrm{BrC}$ ) corresponding to larger ammonium nitrate $\left(f_{\mathrm{NO}_{3}}=0.38 \pm 0.05, f_{\mathrm{NH}_{4}}=0.14 \pm 0.01\right)$ and lower $\mathrm{BC}\left(f_{\mathrm{BC}}=0.01 \pm 0.01\right)$.

In the paper by Gilardoni et al. (2016) we investigated organic aerosol source and identified SOA formation from processing of biomass-burning emissions in the aqueous phase.
We than discussed the climate implication of this aqSOA formation at the light of its optical properties, including AAE. In the present paper we investigated the particle size distribution and spectral optical properties of brown carbon in the ambient aerosol and related these to major aerosol chemical components. By combining the analysis of microphysical and optical properties reported here with the source apportionment study by Gilardoni et al. (2016), we demonstrated that the aqSOA formation adds mass to the atmospheric aerosol in the droplet-mode range.

When exploring consistency of these findings with the literature, our study

i. provides experimental evidence that the size distribution of $\mathrm{BrC}$ associated with the formation of secondary aerosol is dominated by the droplet mode, consistent with recent findings pointing to the role of aqueous reactions within aerosol particles in the formation of $\mathrm{BrC}$;

ii. shows that in the lower troposphere AAE increases with increasing OA-to-BC ratios rather than with increasing $\mathrm{OA}$, contributing to sky radiometer retrieval techniques (e.g., AERONET);

iii. extends to the ambient aerosol dominated by woodburning emissions the dependence of AAE on the BCto-OA ratio previously observed in combustion chamber experiments.

These findings are expected to bear important implications for atmospheric modeling studies and remote sensing observations. Both $\mathrm{BrC}$ number size distribution and the dependence of $\mathrm{AAE}$ on the $\mathrm{BC}$-to-OA ratio can be relevant to parametrize and investigate $\mathrm{BrC}$ in the ambient atmosphere. Findings can be used to infer preliminary chemical information from optical information, as optical techniques are increasingly used to characterize aerosol properties.

\section{Data availability}

All the data presented in this paper are available upon request. Please contact the corresponding author (Francesca Costabile, f.costabile@isac.cnr.it) for further information.

\section{The Supplement related to this article is available online at doi:10.5194/acp-17-313-2017-supplement.}

Acknowledgements. This work was realized in the framework of the SUPERSITO Project, financed by the Emilia-Romagna Region (under the DR 1971/13). The work was partly accomplished in the framework of the DIAPASON ("Desert-dust Impact on Air quality through model-Predictions and Advanced Sensors ObservatioNs") project, funded by the European Commission (LIFE+ 2010 


\section{ENV/IT/391).}

Edited by: R. Sullivan

Reviewed by: three anonymous referees

\section{References}

Alexander, D. T., Crozier, P. A., and Anderson, J. R.: Brown carbon spheres in East Asian outflow and their optical properties, Science, 321, 833-836, 2008.

Andreae, M. O. and Gelencsér, A.: Black carbon or brown carbon? The nature of light-absorbing carbonaceous aerosols, Atmos. Chem. Phys., 6, 3131-3148, doi:10.5194/acp-6-3131-2006, 2006.

Arola, A., Schuster, G., Myhre, G., Kazadzis, S., Dey, S., and Tripathi, S. N.: Inferring absorbing organic carbon content from AERONET data, Atmos. Chem. Phys., 11, 215-225, doi:10.5194/acp-11-215-2011, 2011.

Backman, J., Virkkula, A., Vakkari, V., Beukes, J. P., Van Zyl, P. G., Josipovic, M., Piketh, S., Tiitta, P., Chiloane, K., Petäjä, T., Kulmala, M., and Laakso, L.: Differences in aerosol absorption Ångström exponents between correction algorithms for a particle soot absorption photometer measured on the South African Highveld, Atmos. Meas. Tech., 7, 4285-4298, doi:10.5194/amt7-4285-2014, 2014.

Bahadur, E., Praveen, P. S., Xu, Y., and Ramanathan, V.: Solar absorption by elemental and brown carbon determined from spectral observations, P. Natl. Acad. Sci. USA, 109, 17366-17371, 2012.

Bellouin, N.: Aerosols: The colour of smoke, Nat. Geosci., 7, 619620, 2014.

Bergstrom, R. W., Russell, P. B., and Hignett, P.: Wavelength Dependence of the Absorption of Black Carbon Particles: Predictions and Results from the TARFOX Experiment and implications for the Aerosol Single Scattering Albedo, J. Atmos. Sci., 59, 567-577, 2002.

Bohren, C. F. and Huffman, D. R.: Absorption and Scattering of Light by Small Particles, John Wiley, 232 pp., 1983.

Bond, T. C., Anderson, T. L., and Campbell, D.: Calibration and intercomparison of filter-based measurements of visible light absorption by aerosols, Aerosol Sci. Tech., 30, 582-600, 1999.

Bond, T. C. and Bergstrom, R. W.: Light absorption by carbonaceous particles: An investigative review, Aerosol Sci. Tech., 40, 27-67, 2006.

Bond, T. C., Doherty, S. J., Fahey, D. W., Forster, P. M., Berntsen, T., DeAngelo, B. J., Flanner, M. G., Ghan, S., Kärcher, B., Koch, D., Kinne, S., Kondo, Y., Quinn, P. K., Sarofim, M. C., Schultz, M. G., Schulz, M., Venkataraman, C., Zhang, H., Zhang, S., Bellouin, N., Guttikunda, S. K., Hopke, P. K., Jacobson, M. Z., Kaiser, J. W., Klimont, Z., Lohmann, U., Schwarz, J. P., Shindell, D., Storelvmo, T., Warren, S. G., and Zender, C. S.: Bounding the role of black carbon in the climate system: A scientific assessment, J. Geophys. Res.-Atmos., 118, 5380-5552, doi:10.1002/jgrd.50171, 2013.

Bones, D. L., Henricksen, D. K., Mang, S. A., Gonsior, M., Bateman, A. P., Nguyen, T. B., Cooper, W. J., and Nizkorodov, S. A.: Appearance of strong absorbers and fluorophores in limonene$\mathrm{O}_{3}$ secondary organic aerosol due to $\mathrm{NH}_{4}^{+}$-mediated chemical aging over long time scales, J. Geophys. Res., 115, D05203, doi:10.1029/2009JD012864, 2010.

Brines, M., Dall'Osto, M., Beddows, D. C. S., Harrison, R. M., Gómez-Moreno, F., Núñez, L., Artíñano, B., Costabile, F., Gobbi, G. P., Salimi, F., Morawska, L., Sioutas, C., and Querol, $\mathrm{X}$.: Traffic and nucleation events as main sources of ultrafine particles in high-insolation developed world cities, Atmos. Chem. Phys., 15, 5929-5945, doi:10.5194/acp-15-5929-2015, 2015.

Cappa, C. D., Lack, D. A., Burkholder, J. B., and Ravishankara, A. R.: Bias in filter-based aerosol light absorption measurements due to organic aerosol loading: Evidence from laboratory measurements, Aerosol Sci. Tech., 42, 1022-1032, 2008.

Costabile, F., Birmili, W., Klose, S., Tuch, T., Wehner, B., Wiedensohler, A., Franck, U., König, K., and Sonntag, A.: Spatiotemporal variability and principal components of the particle number size distribution in an urban atmosphere, Atmos. Chem. Phys., 9, 3163-3195, doi:10.5194/acp-9-3163-2009, 2009.

Costabile, F., Barnaba, F., Angelini, F., and Gobbi, G. P.: Identification of key aerosol populations through their size and composition resolved spectral scattering and absorption, Atmos. Chem Phys., 13, 2455-2470, doi:10.5194/acp-13-2455-2013, 2013.

DeCarlo, P. F., Kimmel, J. R., Trimborn, A., Northway, M. J., Jayne, J. T., Aiken, A. C., Gonin, M., Fuhrer, K., Horvath, T., Docherty, K. S., Worsnop, D. R., and Jimenez, J. L.: Field-deployable, high-resolution, time-of-flight aerosol mass spectrometer, Anal. Chem., 78, 8281-8289, 2006.

Ervens, B., Turpin, B. J., and Weber, R. J.: Secondary organic aerosol formation in cloud droplets and aqueous particles (aqSOA): a review of laboratory, field and model studies, Atmos. Chem. Phys., 11, 11069-11102, doi:10.5194/acp-1111069-2011, 2011.

Flores, J. M., Washenfelder, R. A., Adler, G., Lee, H. J., Segev, L., Laskin, J., Laskin, A., Nizkorodov, S. A., Brown, S. S., and Rudich, Y.: Complex refractive indices in the near-ultraviolet spectral region of biogenic secondary organic aerosol aged with ammonia, Phys. Chem. Chem. Phys., 16, 10629-10642, doi:10.1039/C4CP01009D, 2014.

Flowers, B. A., Dubey, M. K., Mazzoleni, C., Stone, E. A., Schauer, J. J., Kim, S.-W., and Yoon, S. C.: Optical-chemicalmicrophysical relationships and closure studies for mixed carbonaceous aerosols observed at Jeju Island; 3-laser photoacoustic spectrometer, particle sizing, and filter analysis, Atmos. Chem. Phys., 10, 10387-10398, doi:10.5194/acp-10-10387-2010, 2010.

Gilardoni, S., Vignati, E., Cavalli, F., Putaud, J. P., Larsen, B. R., Karl, M., Stenström, K., Genberg, J., Henne, S., and Dentener, F.: Better constraints on sources of carbonaceous aerosols using a combined ${ }^{14} \mathrm{C}$ - macro tracer analysis in a European rural background site, Atmos. Chem. Phys., 11, 5685-5700, doi:10.5194/acp-11-5685-2011, 2011.

Gilardoni, S., Massoli, P., Paglione, M., Giulianelli, L., Carbone, C., Rinaldi, M., Decesari, S., Sandrini, S., Costabile, F., Gobbi, G. P., Pietrogrande, M. C., Visentin, M., Scotto, F., Fuzzi, S., and Facchini, M. C.: Direct observation of aqueous secondary organic aerosol from biomass burning emissions, P. Natl. Acad. Sci. USA, 113, 10013-10018, 2016.

Gyawali, M., Arnott, W. P., Lewis, K., and Moosmüller, H.: In situ aerosol optics in Reno, NV, USA during and after the summer 2008 California wildfires and the influence of absorbing and non-absorbing organic coatings on spectral light absorption, At- 
mos. Chem. Phys., 9, 8007-8015, doi:10.5194/acp-9-8007-2009, 2009.

Hinds, W. C.: Aerosol Technology, 2nd Edn., Wiley, New York, 1999.

IPCC: Climate Change 2013: The Physical Science Basis. Contribution of Working Group I to the Fifth Assessment Report of the Intergovernmental Panel on Climate Change, Chapter 7: Clouds and Aerosols, edited by: Stocker, T. F., Qin, D., Plattner, G.-K., Tignor, M., Allen, S. K., Boschung, J., Nauels, A., Xia, Y., Bex, V., and Midgley, P. M., Cambridge University Press, Cambridge, UK and New York, NY, USA, 2013.

Khlystov, A., Stanier, C., and Pandis, S. N.: An Algorithm for Combining Electrical Mobility and Aerodynamic Size Distributions Data when Measuring Ambient Aerosol, Special Issue of Aerosol Science and Technology on Findings from the Fine Particulate Matter Supersites Program., Aerosol Sci. Tech., 38, 229238, 2004.

Lack, D. A. and Langridge, J. M.: On the attribution of black and brown carbon light absorption using the Ångström exponent, Atmos. Chem. Phys., 13, 10535-10543, doi:10.5194/acp13-10535-2013, 2013

Lack, D. A., Cappa, C. D., Covert, D. S., Baynard, T., Massoli, P., Sierau, B., Bates, T. S., Quinn, P. K., Lovejoy, E. R., and Ravishankara, A. R.: Bias in filter-based aerosol light absorption measurements due to organic aerosol loading: Evidence from ambient measurements. Aerosol Sci. Tech., 42, 1033-1041, 2008.

Larsen, B. R., Gilardoni, S., Stenström, K., Niedzialek, J., Jimenez, J., and Belis, C. A.: Sources for PM air pollution in the Po Plain, Italy: II. Probabilistic uncertainty characterization and sensitivity analysis of secondary and primary sources, Atmos. Environ., 50, 203-213, doi:10.1016/j.atmosenv.2011.12.038, 2012.

Laskin, A., Laskin, J., and Nizkorodov, S. A.: Chemistry of Atmospheric Brown Carbon, Chem. Rev., 115, 4335-4382, doi:10.1021/cr5006167, 2015.

Lee, A. K. Y., Zhao, R., Li, R., Liggio, J., Li, S.-M., and Abbatt, J. P. D.: Formation of light absorbing organo-nitrogen species from evaporation of droplets containing glyoxal and ammonium sulfate, Environ. Sci. Technol., 47 12819-12826, doi:10.1021/es402687w, 2013.

Lin, P., Huang, X.-F., He, L.-Y., and Yu, J. Z.: Abundance and size distributions of HULIS in ambient aerosols at a rural site in South China, J. Aerosol Sci., 41, 74-87, 2010.

Lin, Y.-H., Budisulistiorini, S. H., Chu, K., Siejack, R. A., Zhang, H., Riva, M., Zhang, Z., Gold, A., Kautzman, K. E., and Surratt, J. D.: Light-absorbing oligomer formation in secondary organic aerosol from reactive uptake of isoprene epoxydiols, Environ. Sci. Technol., 48, 12012-12021, doi:10.1021/es503142b, 2014

Lin, P., Laskin, J., Nizkorodov, S. A., and Laskin, A.: Revealing brown carbon chromophores produced in reactions of methylglyoxal with ammonium sulfate, Environ. Sci. Technol., 49, 1425714266, 2015.

Liu, P. S., Deng, R., Smith, K. A., Williams, L. R., Jayne, J. T., Canagaratna, M. R., Moore, K., Onasch, T. B., Worsnop, D. R., and Deshler, T.: Transmission efficiency of an aerodynamic focusing lens system: Comparison of model calculations and laboratory measurements for the Aerodyne Aerosol Mass Spectrometer, Aerosol Sci. Tech., 41, 721-733, doi:10.1080/02786820701422278, 2007.
Lu, Z., Streets, D. G., Winijkul, E., Yan, F., Chen, Y., Bond, T. C., Feng, Y., Dubey, M. K., Liu, S., Pinto, J. P., and Carmichael, G. R.: Light absorption properties and radiative effects of primary organic aerosol emissions, Environ. Sci. Technol., 49, 48684877, doi:10.1021/acs.est.5b00211, 2015.

Jacobson, M. Z.: Isolating nitrated and aromatic aerosols and nitrated aromatic gases as sources of ultraviolet light absorption, $\mathrm{J}$. Geophys. Res.-Atmos., 104, 3527-3542, 1999.

Jimenez, J. L., Jayne, J. T., Shi, Q., Kolb, C. E., Worsnop, D. R., Yourshaw, I., Seinfeld, J. H., Flagan, R. C., Zhang, X., Smith, K. A., and Morris, J. W.: Ambient aerosol sampling using the Aerodyne Aerosol Mass Spectrometer, J. Geophys. Res.-Atmos., 108, 1984-2012, doi:10.1029/2001jd001213, 2003.

John, W., Wall, S. M., Ondo, J. L., and Winklmayr, W.: Modes in the size distributions of atmospheric inorganic aerosol, Atmos. Environ., 24A, 2349-2359, 1990.

Meng, Z. and Seinfield, J. H.: On the source of the submicrometer droplet mode of urban and regional aerosols, Aerosol Sci. Tech., 20, 253-265, 1994.

Middlebrook, A. M., Bahreini, R., Jimenez, J. L., and Canagaratna, M. R.: Evaluation of Composition-Dependent Collection Efficiencies for the Aerodyne Aerosol Mass Spectrometer using Field Data, Aerosol Sci. Tech., 46, 258-271, doi:10.1080/02786826.2011.620041, 2012.

Moise, T., Flores, J. M., and Rudich, Y.: Optical Properties of Secondary Organic Aerosols and Their Changes by Chemical Processes, Chem. Rev., 115.10, 4400-4439, doi:10.1021/cr5005259, 2015.

Moosmüller, H., Chakrabarty, R. K., Ehlers, K. M., and Arnott, W. P.: Absorption Ångström coefficient, brown carbon, and aerosols: basic concepts, bulk matter, and spherical particles, Atmos. Chem. Phys., 11, 1217-1225, doi:10.5194/acp-11-12172011, 2011.

Nakayama, T., Kondo, Y., Moteki, N., Sahu, L. K., Kinase, T., Kita, K., and Matsumi, Y.: Size-Dependent Correction Factors for Absorption Measurements using Filter-based Photometers: PSAP and COSMOS, J. Aerosol. Sci., 41, 333-343, 2010.

Noziere, B., Dziedzic, P., and Cordova, A.: Products and kinetics of the liquid-phase reaction of glyoxal catalyzed by ammonium ions $\left(\mathrm{NH}_{4}^{+}\right)$, J. Phys. Chem. A, 113, 231-237, 2009.

Noziere, B., Dziedzic, P., and Cordova, A.: Inorganic ammonium salts and carbonate salts are efficient catalysts for aldol condensation in atmospheric aerosols, Phys. Chem. Chem. Phys., 12, 3864-3872, 2010.

Pohjola, M. A., Pirjola, L., Karppinen, A., Härkönen, J., Korhonen, H., Hussein, T., Ketzel, M., and Kukkonen, J.: Evaluation and modelling of the size fractionated aerosol particle number concentration measurements nearby a major road in Helsinki - Part I: Modelling results within the LIPIKA project, Atmos. Chem. Phys., 7, 4065-4080, doi:10.5194/acp-7-4065-2007, 2007.

Pöschl, U.: Aerosol particle analysis: challenges and progress, Anal. Bioanal. Chem., 375.1, 30-32, doi:10.1007/s00216-002-1611-5, 2003.

Powelson, M. H., Espelien, B. M., Hawkins, L. N., Galloway, M. M., and De Haan, D. O.: Brown carbon formation by aqueous-phase carbonyl compound reactions with amines and ammonium sulfate, Environ. Sci. Technol., 48, 985-993, doi:10.1021/es4038325, 2014. 
Quinn, P. K., Bates, T. S., Coffman, D. J., and Covert, D. S.: Influence of particle size and chemistry on the cloud nucleating properties of aerosols, Atmos. Chem. Phys., 8, 1029-1042, doi:10.5194/acp-8-1029-2008, 2008.

Russell, P. B., Bergstrom, R. W., Shinozuka, Y., Clarke, A. D., DeCarlo, P. F., Jimenez, J. L., Livingston, J. M., Redemann, J., Dubovik, O., and Strawa, A.: Absorption Angstrom Exponent in AERONET and related data as an indicator of aerosol composition, Atmos. Chem. Phys., 10, 1155-1169, doi:10.5194/acp-101155-2010, 2010.

Saleh, R., Hennigan, C. J., McMeeking, G. R., Chuang, W. K., Robinson, E. S., Coe, H., Donahue, N. M., and Robinson, A. L.: Absorptivity of brown carbon in fresh and photo-chemically aged biomass-burning emissions, Atmos. Chem. Phys., 13, 76837693, doi:10.5194/acp-13-7683-2013, 2013.

Saleh, R., Robinson, E. S., Tkacik, D. S., Ahern, A. T., Liu, S., Aiken, A. C., Sullivan, R. C., Presto, A. A., Dubey, M. K., Yokelson, R. J., Donahue, N. M., and Robinson, A. L.: Brownness of organics in aerosols from biomass burning linked to their black carbon content, Nat. Geosci., 7, 647-650, 2014.

Sareen, N., Schwier, A. N., Shapiro, E. L., Mitroo, D., and McNeill, V. F.: Secondary organic material formed by methylglyoxal in aqueous aerosol mimics, Atmos. Chem. Phys., 10, 997-1016, doi:10.5194/acp-10-997-2010, 2010.

Seinfeld, J. H. and Pandis, S. P.: Atmospheric Chemistry and Physics, 2nd Edn., John Wiley, New York, USA, 1232 pp., 2006.

Shapiro, E. L., Szprengiel, J., Sareen, N., Jen, C. N., Giordano, M. R., and McNeill, V. F.: Light-absorbing secondary organic material formed by glyoxal in aqueous aerosol mimics, Atmos. Chem. Phys., 9, 2289-2300, doi:10.5194/acp-9-2289-2009, 2009.
Shinozuka, Y., Clarke, A. D., DeCarlo, P. F., Jimenez, J. L., Dunlea, E. J., Roberts, G. C., Tomlinson, J. M., Collins, D. R., Howell, S. G., Kapustin, V. N., McNaughton, C. S., and Zhou, J.: Aerosol optical properties relevant to regional remote sensing of $\mathrm{CCN}$ activity and links to their organic mass fraction: airborne observations over Central Mexico and the US West Coast during MILAGRO/INTEX-B, Atmos. Chem. Phys., 9, 6727-6742, doi:10.5194/acp-9-6727-2009, 2009.

Song, C., Gyawali, M., Zaveri, R. A., Shilling, J. E., and Arnott, W. P.: Light absorption by secondary organic aerosol from $\alpha$-pinene: Effects of oxidants, seed aerosol acidity, and relative humidity, J. Geophys. Res., 118, 11741-11749, doi:10.1002/jgrd.50767, 2013.

Updyke, K. M., Nguyen, T. B., and Nizkorodov, S. A.: Formation of brown carbon via reactions of ammonia with secondary organic aerosols from biogenic and anthropogenic precursors, Atmos. Environ., 63, 22-31, doi:10.1016/j.atmosenv.2012.09.012, 2012.

Virkkula, A.: Correction of the calibration of the 3-wavelength Particle Soot Absorption Photometer (3גPSAP), Aerosol Sci. Tech., 44, 706-712, 2010.

Zhang, X., Lin, Y. H., Surratt, J. D., Zotter, P., Prévôt, A. S., and Weber, R. J.: Light-absorbing soluble organic aerosol in Los Angeles and Atlanta: A contrast in secondary organic aerosol, Geophys. Res. Lett., 38, L21810, doi:10.1029/2011GL049385, 2011.

Zhang, X., Lin, Y.-H., Surratt, J. D., and Weber, R. J.: Sources, composition and absorption Ångström exponent of light-absorbing organic components in aerosol extracts from the Los Angeles Basin, Environ. Sci. Technol., 47, 3685-3693, 2013. 